\title{
Intuition Talk is Not Methodologically Cheap: Empirically Testing the "Received Wisdom" about Armchair Philosophy
}

\author{
Zoe Ashton, Simon Fraser University \\ Moti Mizrahi, Florida Institute of Technology
}

Forthcoming in Erkenntnis

\begin{abstract}
The "received wisdom" in contemporary analytic philosophy is that intuition talk is a fairly recent phenomenon, dating back to the 1960s. In this paper, we set out to test two interpretations of this "received wisdom." The first is that intuition talk is just talk, without any methodological significance. The second is that intuition talk is methodologically significant; it shows that analytic philosophers appeal to intuition. We present empirical and contextual evidence, systematically mined from the JSTOR corpus and HathiTrust's Digital Library, which provide some empirical support for the second rather than the first hypothesis. Our data also suggest that appealing to intuition is a much older philosophical methodology than the "received wisdom" alleges. We then discuss the implications of our findings for the contemporary debate over philosophical methodology.
\end{abstract}

Keywords: appeals to intuition; armchair philosophy; intuition; Metaphilosophy; philosophical methodology

\section{Introduction}

As Andow (2015a, p. 189) points out, the "received wisdom" in analytic philosophy is that "the word 'intuition' has exploded across analytic philosophy in recent decades" (emphasis added). For example, according to Hintikka (1999, p. 127):

Before the early 1960s, you could scarcely find any overt references, let alone appeals, to intuitions in the pages of philosophical journals and books in the analytical tradition. After the mid-1960s, you will find intuitions playing a major role in the philosophical argumentation of virtually every article or book (emphasis added).

For Hintikka (1998, p. 258), the story of how analytic philosophers started appealing to intuitions goes like this:

Methodologically insecure philosophers began in the 1960s to imitate Chomsky or, rather, to imitate what they took to be Chomsky's methodology. This methodology was perceived as relying heavily on competent speakers' intuitions of the grammaticality of different strings of symbols. Sometimes a grammarian's task was characterized as a 
regimentation of such intuitions. What the philosophers who imitated Chomsky did not initially realize was that he was a closet Cartesian who did have an implicit backing for his appeals to intuition which at least satisfied him. Alas, the vast majority of the philosophers who in our days appeal to intuitions are not Cartesians and do not have any other theoretical backing for their appeals to intuition. Hence they do not offer us any reasons why we should trust any of their conclusions that are directly or indirectly based on appeals to intuition (emphasis added).

Goldman (2007, pp. 2-3) is in agreement with Hintikka when he writes:

As a historical matter, philosophers haven't always described their methodology in the language of intuition. In fact, this seems to be a fairly recent bit of usage. Jaakko Hintikka (1999) traces the philosophical use of "intuition" to Chomsky's description of linguistics' methodology. In the history of philosophy, and even in the early years of analytic philosophy, the terminology of intuition is not to be found. Of course, historical philosophers dealt extensively with intuition in other contexts, but not in the context of appealing to particular examples and their classification. This is not to say that historical philosophers and earlier 20th-century philosophers did not make similar philosophical moves. They did make such moves, they just didn't use the term "intuition" to describe them. [...] Nowadays philosophers routinely rely on intuitions to support or refute philosophical analyses (emphasis added).

The distinction Goldman makes here between the "terminology of intuition" and appeals to intuition is worth noting. Goldman claims that appeals to intuition could, and probably did, occur without the "terminology of intuition" or intuition talk. The search categories we employ follow a similar distinction, i.e., language indicating appeals to intuition and the terminology of intuition. Language indicating appeals to intuition would have existed without this terminology, indicating the two different categories.

Moreover, Goldman is not talking merely about the use of the word 'intuition' by contemporary philosophers in the passage quoted above. Rather, he is also talking about appeals to intuition as a philosophical methodology. This is made clear when, in the opening paragraph of the same paper, Goldman (2007, p. 1) says the following:

One thing that distinguishes philosophical methodology from the methodology of the sciences is its extensive and avowed reliance on intuitions. Especially when philosophers are engaged in philosophical "analysis," they often get preoccupied with intuitions. [...] The evidential weight accorded to intuition is often very high, in both philosophical practice and philosophical reflection (emphasis added).

Similarly, Baz (2012, p. 87) observes that, "For several decades now, philosophers in the mainstream of analytic philosophy pursuing a theory of some subject $x$ (knowledge, necessary truth, causation, intentional action, and so on) have centrally relied on what they themselves have been happy to describe as their own and others people's 'intuitions' of whether or not our concept of $x$, or the word ' $x$ ', applies to this or that particular case, real or imagined" (emphasis added). In line with Hintikka, Goldman, and Baz, Cappelen (2012, p. 50) thinks that 
'Philosophers' use of 'intuition' is a kind of intellectual/verbal virus (or tick) that started spreading about thirty to forty years ago" (emphasis added). ${ }^{1}$

Andow (2015a) does much towards empirically testing the "received wisdom" about the explosion in "intuition." His study focused on comparing intuition talk in philosophy with other fields. He finds that, although the proportions were higher in philosophy, intuition talk was growing at similar rates in fields other than philosophy. In addition, he finds that intuition talk in analytic philosophy did explode at a higher rate than the rest of philosophy. Andow's (2015a) analysis, while fruitful, focuses only on these comparisons and not on the role intuitions actually play in philosophy. In this paper, we follow in Andow's (2015a) footsteps methodologically, but we seek to advance the contemporary debate over philosophical methodology by focusing on the role that intuitions play in philosophical argumentation.

In particular, we think that there are at least two ways to interpret what the aforementioned philosophers have said about the role of intuitions in analytic philosophy.

(L) The linguistic hypothesis: intuition talk in analytic philosophy is just talk that has no methodological significance. As Cappelen puts it, intuition talk in analytic philosophy is just a "verbal tick"; it does not indicate that philosophers use intuitions as evidence in their arguments. According to Cappelen (2012, p. 7), since intuition talk is unclear, insofar as it could be interpreted as "the 'intuitive' of English" or as "the 'intuitive' of a special idiolect, Philosophers'-English," the prevalence of intuition talk in analytic philosophy does not support Centrality, which is the name Cappelen (2012, p. 3) gives to the thesis that "Contemporary analytic philosophers rely on intuitions as evidence (or as a source of evidence) for philosophical theories.",

(M) The methodological hypothesis: intuition talk in analytic philosophy is methodologically significant. In particular, it shows that philosophers appeal to intuitions; that is, they use the content of their intuitions as evidence in their arguments. In other words, intuition talk is prevalent in philosophy, not because it is a "verbal tick," but because philosophers appeal to intuition, i.e., they "rely on intuitions to support or refute philosophical analyses" (Goldman 2007, p. 3).

In this paper, we set out to empirically test these two hypotheses. Instead of relying on casual impressions and selective quotations, however, we will present empirical and contextual evidence, systematically mined from the JSTOR corpus and HathiTrust's Digital Library. Our findings provide some empirical support for (M) rather than (L). Our data also suggest that appealing to intuition is a much older philosophical methodology than the "received wisdom" alleges. We will then discuss the implications of our findings for the contemporary debate over

\footnotetext{
${ }^{1}$ Some think that appeals to intuition are essential to philosophical methodology. For instance, Gutting (1998, p. 7) writes that "Our disagreement about the nature and epistemic authority of intuitions is at root a battle for the preservation of philosophy as an autonomous field of inquiry." Others disagree, of course (see, e.g., Cohnitz and Haukioja 2015, p. 618). On methodological pluralism in philosophy, see Dutilh Novaes (2012, pp. 255-257). ${ }^{2}$ Other "intuition deniers," as Nado (2016, p.782) calls them, who think that "philosophers generally don't employ intuitions as evidence," include Williamson (2007) and Deutsch (2015).
} 
philosophical methodology and the use of intuitions as evidence in philosophical arguments (i.e., appeals to intuition). ${ }^{3}$

\section{Methods}

To see if intuition talk in philosophy is really as recent a phenomenon as the "received wisdom" alleges (circa 1960), and to test (L) and (M) against the historical record of philosophy, we must employ more rigorous research techniques than relying on casual impressions about the state of the field from selective quotations. To this end, JSTOR's Data for Research (dfr.jstor.org) and HathiTrust's Digital Library (hathitrust.org) are useful tools. In doing so, we expand Andow's (2015a) methodology to give us both a picture of the quantitative and qualitative results. These databases allow researchers to search full texts for exact phrases and access the metadata associated with results. Similar to Andow's (2015a) searches, we used these two databases to search for terms, such as 'intuit', 'intuition, 'intuitions', 'intuitive', and 'intuitively' (JSTOR allows for truncation or "wild card" search using intuit*), which are terms that are indicative of intuition talk, through philosophy publications in English. We also used these two databases to search for phrases, such as 'seems that', 'appears that', and 'it seems to me that', which are phrases that are indicative of appeals to intuition, through philosophy publications in English. ${ }^{4}$

There are key differences in how the HathiTrust and JSTOR databases should be used due to differences in composition and construction. The HathiTrust database is constructed by scanning full partner libraries into the database. Different library cataloging and duplicates within libraries result in a number of duplicates within the database. These duplicates are kept by HathiTrust for a number of historical and readability reasons. The costs associated with deduplication and automated recognition of duplicates mean that there is no way to separate the database into distinct matches. As such, the proportions found using HathiTrust are more representative of the database than the discipline. JSTOR does not have a duplicate problem so trends in the database will be representative of trends in the discipline. But it does have a scope problem; the JSTOR database is limited to book reviews and journal articles. This is one of the benefits of pairing the databases, both of which provide some of the most advanced full-text searches available. For each search phrase, we are able to see usage trends through JSTOR proportions and gain contextual insight from the HathiTrust database. Bearing this in mind, we will look at both databases but use their data for complementary purposes. Claims about trends in the discipline will be mainly supported by data from the JSTOR database, whereas contextual evidence about pervasiveness will be mined from the HathiTrust database.

\footnotetext{
${ }^{3}$ In this paper, we are concerned with the epistemology of intuition, or more specifically, with appeals to intuition as a philosophical methodology, which is also known as the method of cases (Baz 2016), not with what intuitions are. As De Cruz (2015, p. 233) puts it, "The method of cases in analytic philosophy involves the construction of scenarios that elicit intuitions. These intuitions are considered as evidence for or against philosophical theories." On intuitions as inclinations to believe, see Sosa (2007) and Ludwig (2007). On intuitions as judgments, see Devitt (2006) and Williamson (2007). On intuitions as intellectual appearances or seemings, analogues to perceptual appearances or seemings, see Bealer (1992) and Pust (2000). On the underlying psychology of the method of cases, see De Cruz (2015).

${ }^{4}$ Unlike Andow (2015a), whose study looks at the use of the word 'intuition' (and its cognates) or intuition talk, we are also interested in the use of intuitions as evidence in philosophical arguments; that is, in appeals to intuition as a philosophical methodology.
} 


\section{Results}

We first set out to test the claim that intuition talk is a recent phenomenon in analytic philosophy, dating back to the 1960s. A search through philosophy articles in the JSTOR corpus shows that intuition talk goes all the way back to the 1800 s and that instances of intuition talk are on the rise. ${ }^{5}$ Similar results are observed from HathiTrust's database, where intuition talk occurs in everything from dissertations to journals. Of the philosophy articles in the JSTOR corpus that mention 'intuition', the earliest was published in The Journal of Speculative Philosophy and is entitled "Intuition vs. Contemplation" (1868). Another article published in The Journal of Speculative Philosophy, entitled "The Spatial Quale" (1879), was written by William James and it contains instances of 'intuit*' such as "These objective spaces may very well not be intuitive..." (p. 84) and "...there can, these authors think, be nothing intuitive about them" (p. 84). Contrary to the "received wisdom," then, it looks like intuition talk in philosophy is not "a fairly recent bit of usage" (Goldman 2007, p. 2). In fact, intuition talk is much earlier than "the mid 1960s" (Hintikka 1999, p. 127); it goes all the way back to the 1800 s.

While philosophers have engaged in intuition talk since at least the 1800s, it is important to see how widespread this practice was. This is where the empirical approach gives us a clearer understanding of prevalence. Both the JSTOR and HathiTrust databases provide data about the number of articles they include in a subject. Using this data, we can find the proportions per decade of philosophy articles which include instances of intuition talk (see Figure 1). Our intuition proportions differ from Andow's (2015a) because we looked at both journal articles and book reviews in the JSTOR database. Arguments are often made in book reviews and we want to consider these arguments as well. As Figure 1 shows, intuition talk has certainly been on the rise, but it was not non-existent to begin with. About $10 \%$ of the JSTOR articles engaged in intuition talk as early as 1800 and more recent decades have seen a growth up to about $30 \%$.

\footnotetext{
${ }^{5}$ We've chosen to look at the results by decade because early years often had so few total publications in the database that decades give a more well-rounded view.
} 
Figure 1. Proportion of philosophy publications containing intuition talk in the JSTOR database (source: JSTOR Data for Research).

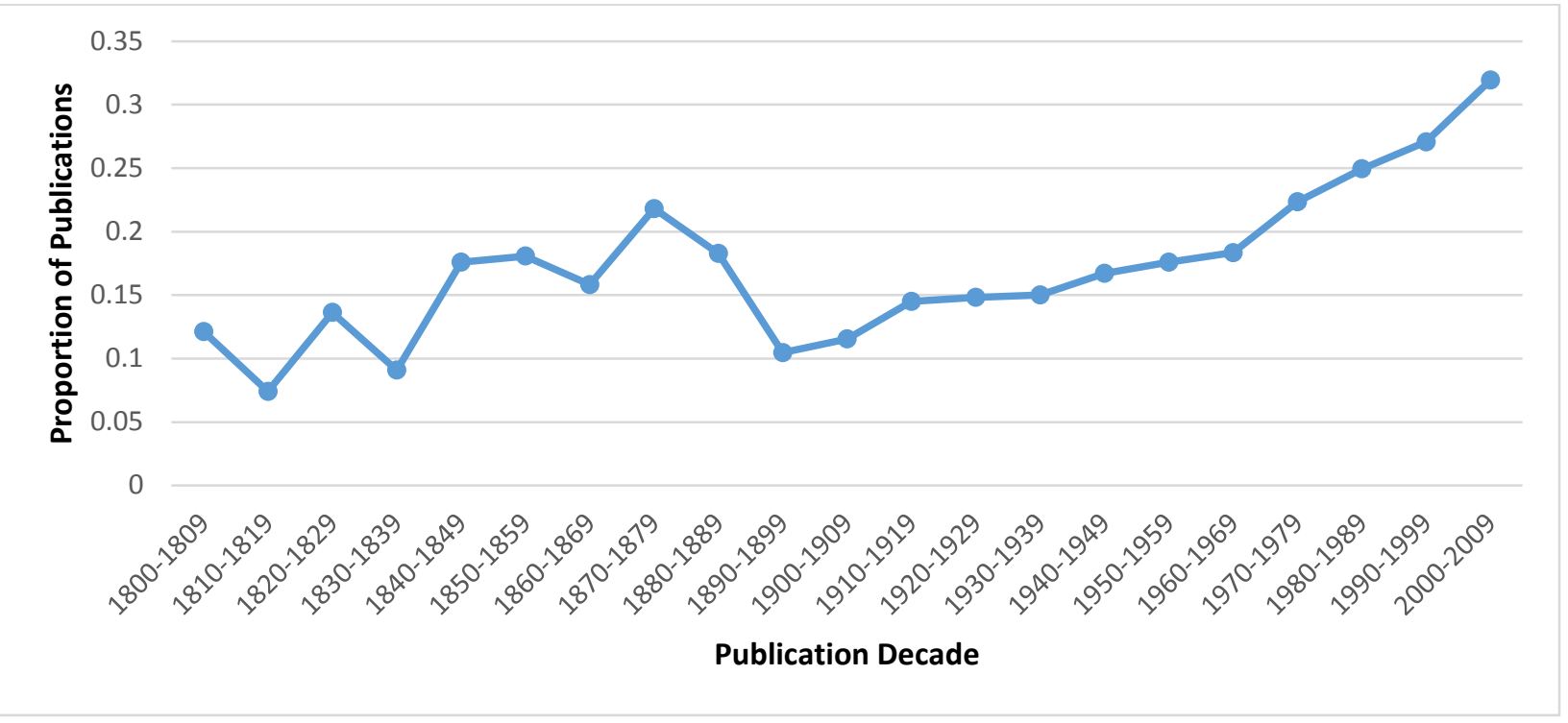

To this it might be objected that the term 'intuition' is used in different ways and that contemporary usage is different from those earlier instances of intuition talk. ${ }^{6}$ Nowadays, it might be argued, when philosophers use the term 'intuition', they mean something like "intellectual appearance" (it intellectually appears to $S$ that $p$ ) or "intellectual seeming" (it intellectually seems to $S$ that $p$ ). According to Brogaard (2014, pp. 387-388), for instance, "intuitions are special kinds of intellectual seemings" and intellectual seemings "are seemings that result from implicit or explicit armchair reasoning, where armchair reasoning is reasoning that involves both a priori principles and past experience." ${ }^{, 7}$ Like Brogaard, many contemporary philosophers think that such intellectual appearances are analogous in epistemically relevant respects to sensory appearances. For instance, according to Sosa (1996, p. 154):

Seemings, then, whether sensory or intellectual, might be viewed as inclinations to believe on the basis of direct experience (sensory) or understanding (intellectual) and regardless of any collateral reasoning, memory, or introspection where the objects of intellectual seeming also present themselves as necessary (emphasis added). ${ }^{8}$

Those who argue that there is an epistemically relevant analogy between intuition and perception do so because, if beliefs based on sense perception are prima facie justified, then, it can be

\footnotetext{
${ }^{6}$ For a useful survey of the ways in which philosophers use 'intuition', see Jenkins (2014, pp. 91-115).

${ }^{7}$ See also Levy (2013, p. 382): "an intuition is an intellectual seeming [...]; to intuit that $p$ is for one to have the relatively forceful impression that $p$ seems to be the case."

${ }^{8}$ See also Bealer (2002) and Chudnoff (2013). Cf. Sarch (2010) and Mizrahi (2014d), (2015b), and (2015c).
} 
argued by analogy that beliefs based on intellectual intuition are prima facie justified as well (see, e.g., Hales 2012, p. 180). ${ }^{9}$

However, even such intuition talk, i.e., as intellectual appearances/seemings (which are supposed to be analogous to sensory appearances/seemings), is much older than "the mid 1960s" (Hintikka 1999, p. 127). A search for 'intellectual appearance' through the JSTOR corpus shows that such usage goes back as far as the early 1800s and the number of instances increases over time. Some of the earlier occurrences of 'intellectual appearance' and similar expressions, such as 'intellectual intuition' and 'common intuition', from the 1800 s include the following (emphasis added):

1. "signifying an intellectual appearance or presence: a manifestation to the understanding" (Hurd 1844, p. 674).

2. "Upon the validity of this intellectual intuition (a direct application of Descartes' appeal to the authority of consciousness), the very axioms of Spinoza's system must wholly rest" (Morell 1847 p. 184).

3. "The more clearly we see any thing to be moral, the more sensibly we feel ourselves under a moral obligation to perform it. This being a matter of common intuition, and universal experience, all that is necessary to convince us of its truth, is to bring it directly before our minds" (Alexander 1852 p. 49).

These philosophers use the phrase 'intellectual appearance' in a way that is very similar (if not identical) to the way contemporary analytic philosophers use it. That is, they use it to talk about the way in which things appear true to the intellect in a manner that is supposed to be analogous to sense perception. ${ }^{10}$

Some might grant that intuition talk goes as far back as the 1800s, as Figure 1 shows, even in the sense of "intellectual appearance" or "intellectual seeming" analogous to sensory appearance or seeming, but insist that these early occurrences of intuition do not necessarily show that nineteenth and twentieth century philosophers appealed to intuition. An appeal to intuition is a particular sort of argument that takes the content of an intellectual appearance or seeming as a premise. In other words, it is an inference from 'it (intellectually) seems to $S$ that $p$ ' to ' $p$ '. Bach (1984) calls this kind of inference "default reasoning." His "take-for-granted" rule states that:

If it seems to me that $p$, then infer that $p$, provided no reason to the contrary occurs to me (Bach 1984, p. 40).

Likewise, Huemer's (2007, p. 30) principle of Phenomenal Conservatism states that:

If it seems to $S$ that $p$, then, in the absence of defeaters, $S$ thereby has at least some degree of justification for believing that $p .^{11}$

\footnotetext{
${ }^{9}$ See also Textor (2009) on linguistic seemings. Cf. Cohnitz and Haukioja (2015).

${ }^{10}$ On the analogy between intuition and perception, see Chudnoff (2013), Hales (2012), and Mizrahi (2014d).

${ }^{11}$ For more on Phenomenal Conservatism, see Moretti (2015). Cf. Mizrahi (2013a), (2014a), (2014b), (2014c), and (2014e).
} 
An appeal to intuition, then, is a kind of argument that proceeds from a premise about what intellectually appears (or seems) to the arguer to a conclusion that the content of this intellectual appearance (or seeming) is true or probably true. The structure of an appeal to intuition is the following:

It seems to $S$ that $p$.

$$
\therefore p
$$

Accordingly, the objection goes, even if nineteenth and twentieth century philosophers engaged in intuition talk, it does not necessarily mean that they appealed to intuitions, i.e., that they used the contents of those intuitions as premises in their arguments. ${ }^{12}$

Indeed, this is probably what Cappelen would say in response to the aforementioned findings, which is why he thinks we should engage in the "charitable reinterpretation" (Cappelen 2012, p. 61) of all intuition talk in analytic philosophy. Against Cappelen, Devitt argues that this "charitable reinterpretation" project is misguided. According to Devitt (2015, p. 677):

we should take philosophers to be using 'intuition' with its ordinary meaning, not some special philosophical meaning, in the absence of persuasive evidence that they are not so using it.

The ordinary meaning of 'intuition', according to Devitt (2015, p. 674), is "immediate judgment, without reasoning or inference." When analytic philosophers introduce a term, they usually define it. If they use a common term without explaining it, they are probably using it in its ordinary sense. Devitt illustrates this point by referring to Kripke's arguments in Naming and Necessity (1980), given that these arguments received a great deal of attention from Cappelen. ${ }^{13}$

If [in using 'intuition' terminology] Kripke had meant 'pretheoretic', he would have said 'pretheoretic'! Kripke is a very precise philosopher. Since Kripke engages in 'intuition'talk without explaining it, the talk has its ordinary sense. So, trying to reinterpret this talk is a misguided enterprise. And I think that we should say much the same about the 'intuition'-talk of the other philosophers cited (Devitt 2015, p. 684).

Devitt (2015, p. 692) even asked Kripke himself “whether Kripke’s judgments seemed immediately true to him, without reasoning" (emphasis added). Kripke's response was that they did seem true to him.

Accordingly, we think that we can address the aforementioned objection empirically by searching for terms and phrases that indicate appeals to intuition as opposed to mere intuition talk, and that these phrases are 'seems that', 'it seems to me that', and the like. For if "the ordinary meaning of 'intuition' is: immediate judgment, without reasoning or inference" (Devitt 2015, p. 674; emphasis in original), and when philosophers engage in intuition talk they mean to say that their judgments seem immediately true to them (Devitt 2015, p. 692), then occurrences of 'seems that' should be pretty good indicators of instances in which philosophers appeal to

\footnotetext{
12 Thanks to an anonymous reviewer to pressing this point about the difference between language and methodology. For more on appeals to intuition, see Feltz (2008) and Mizrahi (2012), (2013b), and (2015a).

${ }^{13}$ See also Deutsch (2015), pp. 105-110.
} 
intuitions. Here is an example from Kripke's Naming and Necessity (1980) of such an occurrence of 'it seems to me that': "it seems to me that such a situation would be a situation in which there was light, but people could not see it" (Kripke 1980, p. 130; emphasis added). The ordinary meaning of 'intuition', then, as "immediate judgment" that "seems true without any [...] support" from argument (Devitt 2015, p. 674; emphasis in original), suggests that 'it seems that' and similar phrases should be pretty good indicators of appeals to intuition, and so we should search for such phrases in the JSTOR and HathiTrust databases. Given that there are no reasons to "charitably reinterpret" intuition talk in philosophy, as Devitt $(2015$, p. 684) argues, and given that a "judgment's being intuitive simply implies that it seems true without argument" (Devitt 2015 , p. 694), usage of 'seems' and its variants should be taken as philosophers reporting judgments that seem true to them.

There are two more reasons to search for 'seems that' and the like as pretty good indicators not merely of intuition talk but of appeals to intuition. First, in addition to the ordinary meaning of 'intuition', the nature of intuition also suggests that 'it seems that' and similar phrases should be pretty good indicators of appeals to intuition. As we have mentioned above, many contemporary philosophers think of intuitions as intellectual seemings or appearances, analogous to perceptual seemings or appearances. If intuitions are intellectual seemings, then, when one says that it seems to one that $p$, one is reporting having an intuition with the content $p$. As Levy (2013, p. 382) puts it, "to intuit that $p$ is for one to have the relatively forceful impression that $p$ seems to be the case" (emphasis added). Accordingly, when a philosopher like Kripke (1980, p. 147) says "that just as it seems that the brain state could have existed without any pain, so it seems that the pain could have existed without the corresponding brain state" (emphasis added), we should take him to be reporting an intellectual seeming whose content is then used as a premise in a philosophical argument. Second, Bach's "take-for-granted" rule and Huemer's principle of Phenomenal Conservatism also suggest that variations of 'it seems that' should be pretty good indicators of appeals to intuition. For, according to these principles, that one has an intellectual seeming that $p$ is supposed to provide defeasible evidence for $p$.

In addition to these theoretical reasons to search for 'seems that', 'appears that' and 'it seems to me that' as pretty good indicators of appeals to intuition in philosophical practice, there are also empirical (specifically, textual) reasons for doing so. According to Cappelen, one of the essential features of intuition is supposed to be its "rock-bottom" evidential status. But Cappelen (2012, p. 112) denies that intuitions "serve as a kind of rock bottom in philosophical argumentation" such that intuitions "justify, but need no justification." Cappelen, like Deutsch (2009), claims that philosophers do not rely on the content of their intuitive judgments as "rockbottom" justification, but rather support that content with further argumentation. Nado (2016, p. 795) calls this "the argument from argumentation," and points out that "both [Cappelen and Deutsch] offer alternative pictures of philosophers' use of thought experiments, emphasizing the role of argumentation and minimizing the role of brute intuition-mongering." Since the argument from argumentation is an argument from case studies (Cappelen uses Lehrer's Trutemp case and Deutsch uses Kripke's Gödel-Schmidt case to make this argument), which, for all we know, may not even be representative of philosophical practice in general, it is enough to find one counterexample in order to weaken its force. Consider, then, the following appeal to intuition from Anscombe (1966, p. 208): 
The nerve of Mr. Bennett's argument is that if A results from your not doing B, then A results from whatever you do instead of doing B. While there may be much to be said for this view, still it does not seem right on the face of it (emphasis added).

In this case, one cannot claim that Anscombe supports her intuitive judgment that Mr. Bennett's view is not right with further argumentation because there is no further text; this is the entire note as published in Analysis.

For these theoretical and empirical (textual) reasons, we have searched through the JSTOR and HathiTrust databases for phrases, such as 'seems that', 'appears that', and 'it seems to me that', which should give us a pretty good indication of whether nineteenth and twentieth century philosophers simply mentioned intuitions or appealed to intuitions. ${ }^{14} \mathrm{We}$ have found that phrases signaling appeals to intuition have increased significantly since the 1900s. However, such phrases are much older than the "received wisdom" would have us believe. We can find indicators of appeals to intuition from the 1800s in both the HathiTrust and JSTOR databases. The HathiTrust database searches give us an idea of the variety of mediums where these indicators of appeals to intuition occurred. Results range from books to dissertations in most decades.

One might argue that although nineteenth and twentieth century philosophers used intuition terminology as well as indicators of appeals to intuition, the latter were more the exception than the rule. Such a claim could be supported by the high increase in the number of indicators over time. However, these proportions show that not only did indicators of appeals to intuition occur in the early 1800s, they appeared in proportions too high to dismiss early occurrences as outliers (see Figure 2). This suggests that appealing to intuition was an acceptable methodology even as early as the 1800 s, provided that phrases such as 'it seems that' and the like are indeed pretty good indicators of appeals to intuition.

\footnotetext{
${ }^{14}$ For more phrases that count as 'intuition'-terminology, such as 'see', 'grasp', and 'strike', see Bengson (2014).
} 
Figure 2. Proportion of philosophy publications in the JSTOR database with phrases indicating appeals to intuition (source: JSTOR Data for Research).

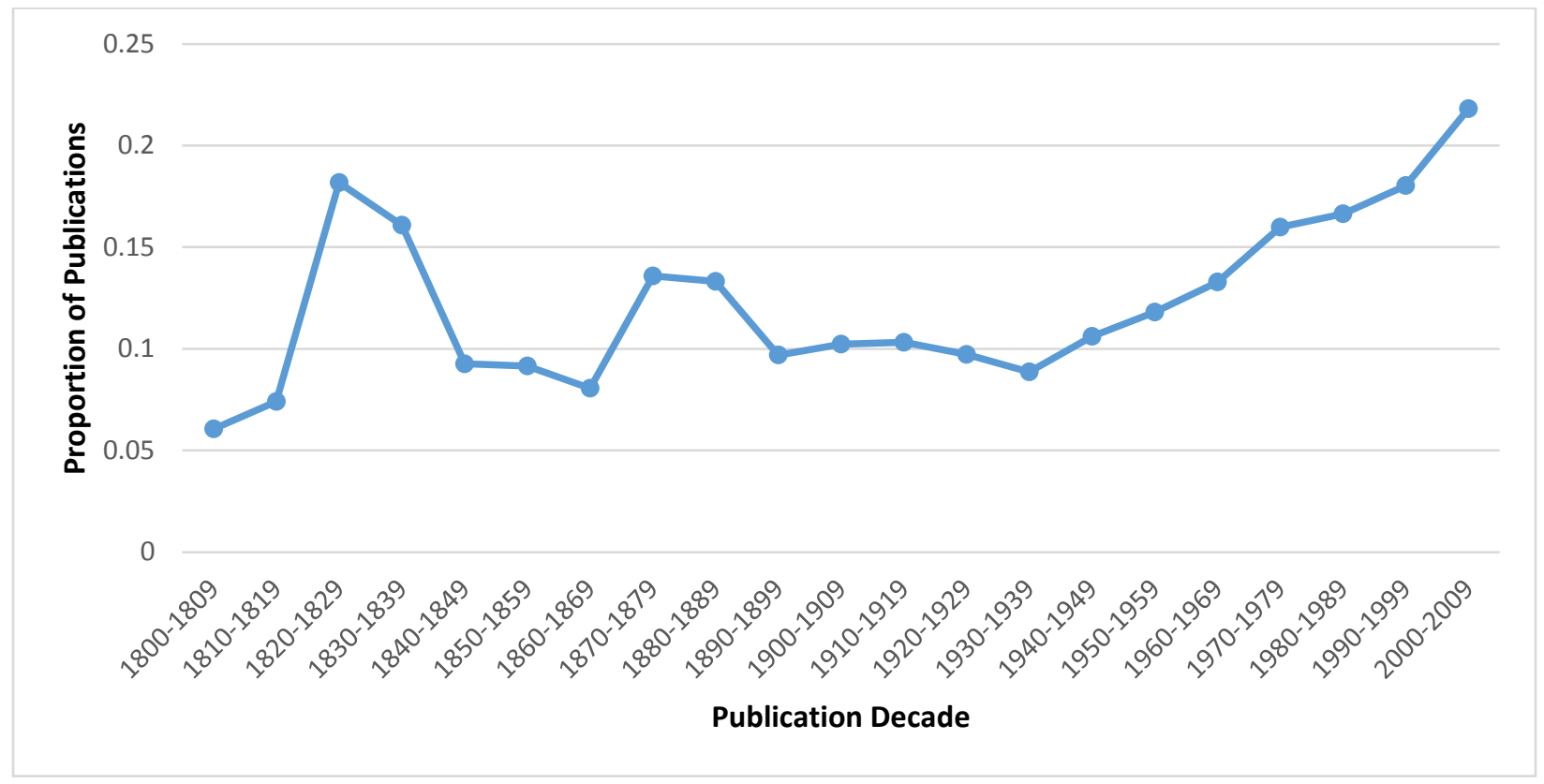

Moreover, a closer look at some of the earliest occurrences of 'it seems that' and the like in the JSTOR database reveals that such phrases are often used to signal a premise, $p$, that is supposed to be accepted because the author has a "relatively forceful impression that $p$ seems to be the case" (Levy 2013, p. 382). Here are a couple of examples of such usage from the JSTOR database (emphasis added):

1. "To say, that space must have existence, because it has some properties, for instance, penetrability, or the capacity of receiving bodies; seems to me the same, as to say, that silence must be something, because it has the property of admitting sound" (Kirwan 1806 , p. 205).

2. "when a man is bidden, in any particular case, to 'trust to his conscience' it commonly seems to be meant that he should exercise a faculty of judging morally this particular case without reference to general rules" (Sidgwick 1876, p. 563). ${ }^{15}$

Results from the HathiTrust database show us how pervasive such usage is, as well as the context of such usage. Examples can be found in everything from books to dissertations. The first two examples below are from books and the last two are from a dissertation:

\footnotetext{
${ }^{15}$ In The Methods of Ethics (1874), Sidgwick characterizes intuitionism as the moral theory whose "rules are thought to be ascertained by direct intuition of the actions themselves." For example, I know that I ought to tell the truth, on this view, since it seems to me that I ought to tell the truth. For more on intuitionism, see Kaspar (2012).
} 
1. "For it seems to me at present, that if there is an External World, one or other of these Accounts of Vision must needs be true, that is Fact" (Collier 1836, p. 94). ${ }^{16}$

2. "I think, it appears, that to pursue what is good upon the whole, and to avoid what is ill upon the whole, is a rational principle of action" (Reid 1819, p. 252).

3. "It seems evident that thought does somehow 'lay hold of reality"' (Cunningham 1918, p. 42).

4. "It seems that the only difference between mind and what is not mind is a matter of grouping" (Cunningham 1918, p. 61).

Compare these occurrences of 'it seems that' to a contemporary instance such as the following one from Kripke's Naming and Necessity (1980, p. 113): "It seems to me that anything coming from a different origin would not be this object" (emphasis added). Accordingly, these philosophers use phrases, such as 'appears that' and 'seems that', in a way that is very similar (if not identical) to the way contemporary analytic philosophers use such phrases. That is, they use phrases such as 'it seems to me that' and the like to signal that what follows the 'that' is a premise that seems true to them. On the assumption that phrases such as 'it seems that' and the like are indeed pretty good indicators of appeals to intuition, this means that these philosophers do not simply mention intuitions. Rather, they appeal to intuitions. For "to intuit that $p$ is for one to have the relatively forceful impression that $p$ seems to be the case" (Levy 2013, p. 382).

Now that we have empirical and contextual evidence to show that both intuition talk, as indicated by 'intuit' and its cognates, and appeals to intuition, as indicated by 'it seems that' and the like, go back to the 1800s, we also want to determine whether our data provide some empirical support for (L) or (M). If (L) is correct, and intuition talk is independent of any methodological factors, we would expect to find little or no correlation between intuition talk and appeals to intuition. This is because (L) claims that intuition talk is independent of appeals to intuition. Empirically, the independence of two variables implies zero correlation between them. In order to test this, we compared the proportions of intuition talk and appeals to intuition in the JSTOR database (see Figure 3). We calculated the Pearson correlation coefficient which is a measure of linear correlation between two variables. The coefficient ranges from -1 to 1 where 0 implies no correlation, 1 is a perfect positive correlation, and -1 is a perfect negative correlation. For the decades from 1800 to 2009, the coefficient was 0.67 , implying a moderately strong positive correlation. Considering the small number of publications available in early decades, a high variation is expected and we think it is appropriate to look at more stable periods separately. The first year with over 100 articles in the JSTOR database was 1876, so we also looked at correlations post-1870. The correlation for decades post-1870 was 0.96 . We also checked post1870 correlations by year, to decrease error caused by small sample size. In the post-1870 data, there are only 14-decade data points but 144 -year data points. This post-1870 yearly correlation coefficient was 0.91 . With a moderately strong positive correlation since 1800 and a very strong positive correlation in post-1870 years, (L) cannot be supported by the empirical data. Our results provide some empirical support for (M) because, even though correlation cannot tell us about the underlying causes, it does tell us that intuition talk is not independent of appeals to intuition.

${ }^{16}$ Collier (1836) was first published in 1713. 
Figure 3. Proportions of intuition talk and appeals to intuition in the JSTOR philosophy database (source: JSTOR Data for Research).

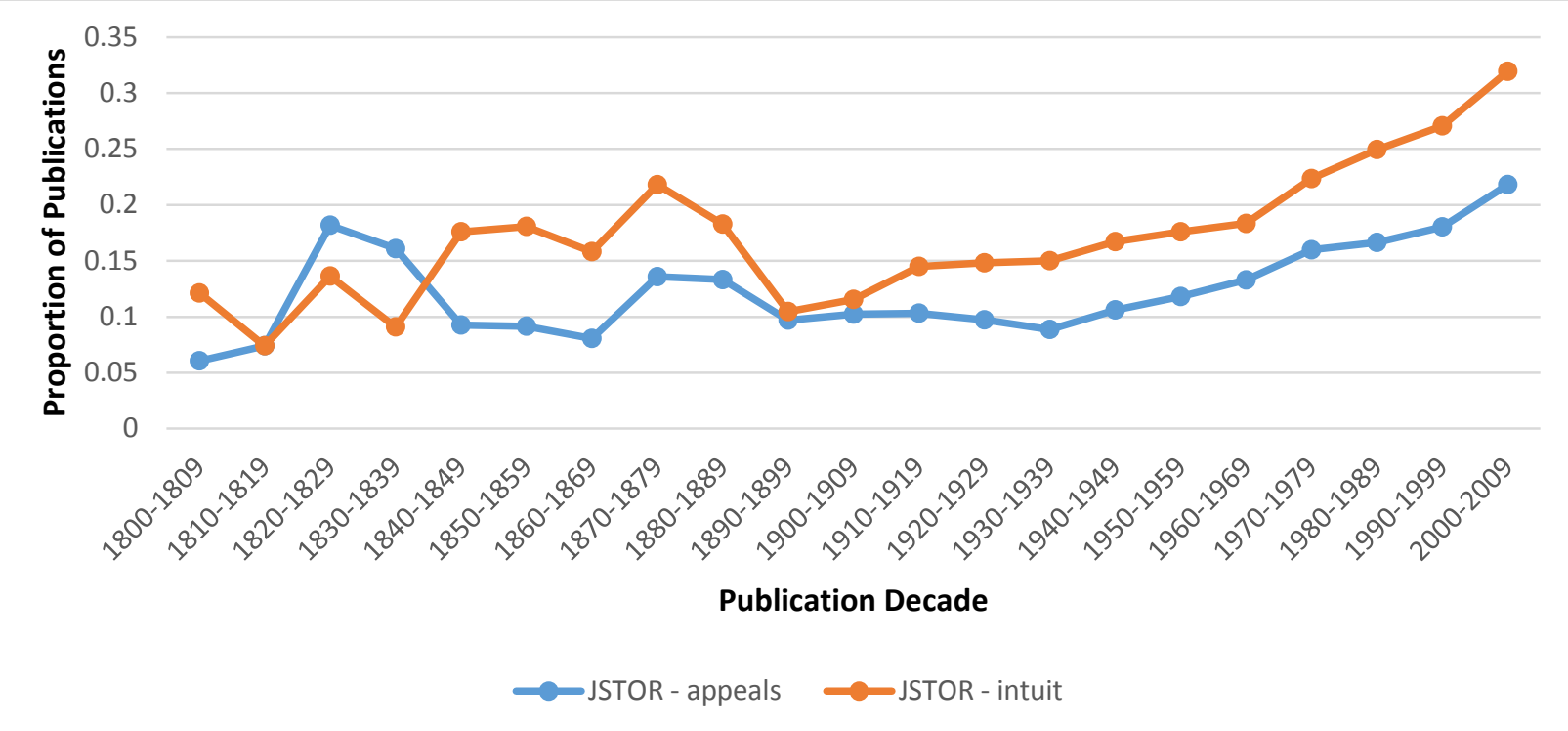

To sum up, the key findings of our survey of the JSTOR and HathiTrust databases are as follows:

1. Intuition talk (where indicators of intuition talk include 'intuit', 'intuition, 'intuitions', 'intuitive', and 'intuitively') in philosophy is not as recent as the "received wisdom" alleges (circa 1960s); it goes as far back as the 1800s;

2. Nineteenth and twentieth century philosophers appealed to intuition (where indicators of appeals to intuition include 'it seems that', 'it appears that', and 'it seems to me that') in argumentative contexts;

3. The proportion of publications in which philosophers appeal to intuition (as indicated by 'it seems that', 'it appears that', and 'it seems to me that') shows that the practice was accepted and fairly common, even early in the 1800s;

4. There is a positive correlation between intuition talk (as indicated by 'intuit', 'intuition, 'intuitions', 'intuitive', and 'intuitively') and appeals to intuition (as indicated by 'it seems that', 'it appears that', and 'it seems to me that').

In the next section, we discuss the implications of our findings for the contemporary debate over philosophical methodology and the use of intuitions as evidence in philosophical arguments.

\section{Discussion}

Since its publication, Cappelen's book, Philosophy Without Intuitions (2012), received a great deal of attention from philosophers, ${ }^{17}$ including special issues devoted to critiques of his

\footnotetext{
${ }^{17}$ According to Google Scholar, it was cited 258 times (last checked 05 February 2017).
} 
arguments as well as his replies to critics. Against Cappelen's (2012, p. 50) claim that "Philosophers' use of 'intuition' is a kind of intellectual/verbal virus (or tick)," some have argued that philosophers do rely on intuitions. For instance, Devitt (2015) examines cases similar to those that Cappelen examines, but draws the conclusion that philosophers do rely on intuitions in philosophical practice. ${ }^{18}$ Similarly, Chalmers $(2014$, p. 535) "find[s] it fairly obvious that many philosophers, including [himself], appeal to intuitions." ${ }^{19}$ Clearly, simply insisting that it is obvious that philosophers appeal to intuitions is not going to convince Cappelen and the other “intuition deniers" (Nado 2016, p. 782), such as Deutsch (2015) and Williamson (2007). For this reason, we submit, our empirical results are important.

We think that our data provide some empirical evidence against Cappelen's (2012, p. 50) claim that "Philosophers' use of 'intuition' is a kind of intellectual/verbal virus (or tick)," as well as against the other "intuition deniers" who think that "philosophers generally don't employ intuitions as evidence" (Nado 2016, p. 782), and lend some empirical support to those who argue that philosophers do appeal to intuitions in philosophical practice. For, as we reported in Section 3 , we have found a positive correlation between intuition talk, as indicated by the term 'intuition' and its cognates ('intuit', 'intuition, 'intuitions', 'intuitive', and 'intuitively') and appeals to intuition, as indicated by the phrases 'it seems that', 'it appears that', and 'it seems to me that'. This positive correlation between intuition talk and appeals to intuition is precisely what we would expect if (M) is true; that is, if intuition talk is methodologically significant. On the other hand, this positive correlation between intuition talk and appeals to intuition is not what we would expect if (L) is true; that is, if intuition talk is just talk, or a "verbal tick," without any methodological significance. Rather than simply insist that "philosophers do indeed rely on what they call 'intuitions' as evidence" (Devitt 2015, p. 688), then, one could cite the results of our study as some empirical evidence in support of the thesis that "[c]ontemporary analytic philosophers rely on intuitions as evidence (or as a source of evidence) for philosophical theories" (Cappelen 2012, p. 3).

Some might object that our results do not really favor (M) over (L) because (L) predicts precisely what we have found. That is, on $(\mathrm{L})$, too, we should expect to find a positive correlation between intuition talk, as indicated by the term 'intuition' and its cognates ('intuit', 'intuition, 'intuitions', 'intuitive', and 'intuitively') and appeals to intuition, as indicated by the phrases 'it seems that', 'it appears that', and 'it seems to me that'. But this is mistaken. This objection only holds if we take both intuition talk and the language indicating appeals to intuition to be of the same category of Cappelen's "verbal tick." This is an assumption Cappelen admits and it would allow (L) to predict the same correlations found here. But there are good reasons for thinking this assumption is not actually the case. In Section 3, we provided arguments for thinking that when philosophers talk about intuition, it should be taken in the usual sense of the word. In addition, when they use phrases like 'it seems to me that', these philosophers are actually appealing to intuition in their arguments. As such, the language indicating appeals to

\footnotetext{
${ }^{18}$ Like Devitt, Climenhaga (forthcoming in Mind) examines arguments from Kripke's Naming and Necessity (1980), which are the arguments that Cappelen examines as well, and concludes that philosophers do rely on intuitions as evidence.

${ }^{19}$ Cf. Cappelen's (2014) reply to Chalmers (2014). See also Nado (2016) for a critical discussion of arguments put forth by those she calls "the intuition deniers."
} 
intuition cannot be solely a "verbal tick." In other words, since appeals to intuition could, and probably did, occur without the "terminology of intuition" or intuition talk, as Goldman (2007, pp. 2-3) points out, appeals to intuition cannot be a proper subset of intuition talk. Because these two categories are now distinct--where language indicating appeals to intuition is not solely a "verbal tick" and intuition talk is still in question--(L) cannot predict the correlations we have found.

As an anonymous reviewer rightly points out, it is important to emphasize the limits of our empirical approach. Since we set out to empirically test hypotheses (L) and (M), our results cannot--and should not--be read as either a conclusive refutation of (L) or a demonstration that (M) is true. Like any empirical argument that seeks to confirm or disconfirm a hypothesis, our argument relies on auxiliary assumptions that can be challenged. As we have mentioned above, the most important one is the assumption that phrases such as 'it seems that' and the like are indeed pretty good indicators of appeals to intuition. As we have also mentioned in Section 3 , however, there are both theoretical and empirical reasons to think that this assumption should be granted for the purposes of our empirical survey, which points to a positive correlation between intuition talk, as indicated by the term 'intuition' and its cognates ('intuit', 'intuition, 'intuitions', 'intuitive', and 'intuitively') and appeals to intuition, as indicated by the phrases 'it seems that', 'it appears that', and 'it seems to me that'.

It is also worth emphasizing the implications of this positive correlation between intuition talk (i.e., 'intuit' and its cognates) and appeals to intuition (i.e., 'it seems that' and the like). Because the correlation is positive, it means that rise in one variable is a good predictor of rise in the other variable. There may be a number of causes for this type of correlation and we cannot determine causation from correlation alone. But we do know that the underlying connection between the variables is not a negative one. So as philosophers engage in more intuition talk, they do not stop appealing to intuition. This is somewhat surprising given that appeals to intuition produce incompatible results. Clearly, intuition talk is more representative of what philosophers are doing than discussions on what they should be doing. This may be because the advent of experimental philosophy has only recently caused a surge in debates over philosophical methodology. Whatever the underlying connection between intuition talk and appeals to intuition, intuition talk is not reducing appeals to intuition on its own.

Some may grant that appealing to intuition is a much older philosophical method than the "received wisdom" alleges, as our results suggest, but insist that philosophers have no alternative methods, which is why intuition talk is methodologically significant; philosophers have no choice but to appeal to intuitions. ${ }^{20}$ This response to our results is inadequate for several reasons. First, even if it is true that philosophers have no other methods, it does not follow that appealing to intuition is a good or reliable method. Likewise, even if it is true that philosophers have no other methods, it does not follow that they should use the method of appealing to intuitions. So this argument is a non sequitur (see Mizrahi 2015b and 2015c).

Second, it is not true that philosophers have no other methods besides appealing to intuition. According to Dutilh Novaes (2012, p. 255), "not only is there room for distinct

\footnotetext{
${ }^{20}$ See Ichikawa's (2013) discussion of what he calls the "what else?" argument. See also Nado (2016).
} 
methodological approaches in philosophy but also that they should be combined in one and the same investigation" (emphasis in original). In addition to what she calls "traditional methods," i.e., conceptual (a priori) reflection and analysis, Dutilh Novaes (2012, pp. 250-254) identifies the following methods:

1. Formal methods: the application of mathematical and logical formalisms to philosophical questions (e.g., formal epistemology and formal semantics);

2. Historical methods: the use of the history of philosophy to understand philosophically relevant concepts (e.g., historical epistemology and HPS);

3. Empirical methods: informing philosophical discussions with empirical results from the sciences (e.g., moral psychology and experimental philosophy).

So, it is not true that philosophers have no other methods to use. Even if it were true, it would not follow that appealing to intuition is a reliable method or that philosophers should appeal to intuition.

\section{Conclusion}

In this paper, through a systematic survey of the JSTOR and HathiTrust databases, we have found that:

1. Intuition talk (where indicators of intuition talk include 'intuit', 'intuition, 'intuitions', 'intuitive', and 'intuitively') in philosophy is not as recent as the "received wisdom" alleges (circa 1960s); it goes as far back as the 1800s;

2. Nineteenth and twentieth century philosophers appealed to intuition (where indicators of appeals to intuition include 'it seems that', 'it appears that', and 'it seems to me that') in argumentative contexts;

3. The proportion of publications in which philosophers appeal to intuition (as indicated by 'it seems that', 'it appears that', and 'it seems to me that') shows that the practice was accepted and fairly common, even early in the 1800s;

4. There is a positive correlation between intuition talk (as indicated by 'intuit', 'intuition, 'intuitions', 'intuitive', and 'intuitively') and appeals to intuition (as indicated by 'it seems that', 'it appears that', and 'it seems to me that').

We have argued that our findings provide some empirical support to the methodological hypothesis (M), according to which intuition talk shows that philosophers appeal to intuitions rather than the linguistic hypothesis (L), according to which intuition talk is just talk. We think that our empirical results can help advance the methodological debate over the role of intuitions as evidence in philosophy. Rather than simply insist that "philosophers do indeed rely on what they call 'intuitions' as evidence" (Devitt 2015, p. 688), or assert that it is obvious that philosophers appeal to intuitions (Chalmers 2014, p. 535), which is not obvious to "intuition deniers" like Cappelen (2012), those who think that philosophers do appeal to intuitions can now cite our results as some empirical evidence for the claims that philosophers do appeal to intuitions and that they have been doing so since the 1800s. Andow's (2015b) qualitative results indicate that the way in which philosophers use intuition talk in explanatory contexts is similar to 
that of other academics. So while the results here are focused on philosophy, it may be that similar methodological ties could be found in other disciplines. This is an open question and further work will need to be done to determine if this is indeed the case.

\section{References}

Alexander, A. (1852). Outlines of Moral Science. Bedford, MA: Applewood Books.

Andow, J. (2015a). How “Intuition” Exploded. Metaphilosophy 46 (2): 189-212.

Andow, J. (2015b). How Distinctive is Philosophers' Intuition Talk? Metaphilosophy 46 (4): 515-538.

Anscombe, G. E. M. (1966). A Note on Mr. Bennett. Analysis 26 (6): 208.

Bach, K. (1984). Default Reasoning: Jumping to Conclusions and Knowing when to Think Twice. Pacific Philosophical Quarterly 65 (1): 37-58.

Baz, A. (2012). When Words Are Called for: A Defense of Ordinary Language Philosophy. Cambridge, MA: Harvard University Press.

Baz, A. (2016). Recent Attempts to Defend the Philosophical Method of Cases and the Linguistic (Re)turn. Philosophy and Phenomenological Research 92 (1): 105-130.

Bealer, G. (1992). The Incoherence of Empiricism. Proceedings of the Aristotelian Society 66: 99-143.

Bealer, G. (2002). A Theory of the A Priori. Pacific Philosophical Quarterly 81 (1): 1-30.

Bengson, J. (2014). How Philosophers Use Intuition and 'Intuition'. Philosophical Studies 171 (3): 555-576.

Brogaard, B. (2014). Intuitions as Intellectual Seemings. Analytic Philosophy 55 (4): 382-393.

Cappelen, H. (2012). Philosophy without Intuitions. Oxford: Oxford University Press.

Cappelen, H. (2014). Replies to Weatherson, Chalmers, Weinberg, and Bengson. Philosophical Studies 171 (3): 577-600.

Chalmers, D. J. (2014). Intuitions in Philosophy: A Minimal Defense. Philosophical Studies 171 (3): 535-544.

Chudnoff, E. (2013). Intuitive Knowledge. Philosophical Studies 162 (2): 359-378.

Climenhaga, N. (forthcoming). Intuitions are used as Evidence in Philosophy. Mind. Available at http://philpapers.org/rec/CLIIAU.

Cohnitz, D. and Haukioja, J. (2015). Intuitions in Philosophical Semantics. Erkenntnis 80 (3): 617-641.

Collier, A. (1836). Clavis Universalis: Or a New Inquiry After Truth. Edinburgh: Ballantyne and Co. 
Cunningham, H. (1918). Three Types of Logical Theory. PhD Dissertation, The University of Chicago.

De Cruz, H. (2015). Where Philosophical Intuitions Come from. Australasian Journal of Philosophy 93 (2): 233-249.

Deutsch, M. E., (2009). Experimental Philosophy and the Theory of Reference. Mind and Language 24 (4): 445-466.

Deutsch, M. E. (2015). The Myth of the Intuitive: Experimental Philosophy and Philosophical Method. Cambridge, MA: MIT Press.

Devitt, M. (2006). Intuitions. In V. G. Pin, J. I. Galparaso, and G. Arrizabalaga (eds.), Ontology Studies: Proceedings of the VI International Ontology Congress (pp. 169-176). San Sebastian, Spain: Universidad del Pais Vasco.

Devitt, M. (2015). Relying on Intuitions: Where Cappelen and Deutsch Go Wrong. Inquiry 58 (7-8): 669-699.

Dutilh Novaes, C. (2012). Formal Languages in Logic: A Philosophical and Cognitive Analysis. New York: Cambridge University Press.

Feltz, A. (2008). Problems with the Appeal to Intuition in Epistemology. Philosophical Explorations 11 (2): 131-141.

Goldman, A. I. (2007). Philosophical Intuitions: Their Target, Their Source, and Their Epistemic Status. Grazer Philosophische Studien 74 (1): 1-26.

Gutting, G. (1998). Rethinking Intuition: A Historical and Metaphilosophical Introduction. In Michael R. DePaul and William Ramsey (eds.), Rethinking Intuition: The Psychology of Intuitions and Its Role in Philosophical Inquiry (pp. 3-14). Lanham: Rowman \& Littlefield.

Hales, S. D. (2012). The Faculty of Intuition. Analytic Philosophy 53 (2): 180-207.

Hintikka, J. (1998). Who Is About to Kill Analytic Philosophy? In A. Biletzki and A. Matar (eds.), The Story of Analytic Philosophy: Plot and Heroes (pp. 253-269). New York: Routledge.

Hintikka, J. (1999). The Emperor's New Intuitions. The Journal of Philosophy 96 (3): 127-147.

Huemer, M. (2007). Compassionate Phenomenal Conservatism. Philosophy and Phenomenological Research 74 (1): 30-55.

Hurd, J. R. (1844). Hyponoia; Or, Thoughts on a Spiritual Understanding of the Apocalypse, Or Book of Revelation. New York: Leavitt, Trow \& Co.

Ichikawa, J. (2013). Review of Philosophy without Intuitions. International Journal for Philosophical Studies 21 (1): 111-116.

Jenkins, C. S. I. (2014). Intuition, 'Intuition', Concepts and the A Priori. In Anthony R. Booth and Darrell P. Rowbottom (eds.), Intuitions (pp. 91-115). New York: Oxford University Press.

Kaspar, D. (2012). Intuitionism. New York: Bloomsbury. 
Kirwan, R. (1806). On Space and Duration. The Transactions of the Royal Irish Academy 10: 189-227.

Kripke, S. A. (1980). Naming and Necessity. Cambridge, MA: Harvard University Press.

Levy, N. (2013). Intuitions and Experimental Philosophy: Comfortable Bedfellow. In Matthew C. Haug (ed.), Philosophical Methodology: The Armchair or the Laboratory? (pp. 381-415).

New York: Routledge.

Ludwig, K. (2007). The Epistemology of Thought Experiments: First Person versus Third Person Approaches. Midwest Studies in Philosophy 31 (1): 128-159.

Mizrahi, M. (2012). Intuition Mongering. The Reasoner 6 (11): 169-170.

Mizrahi, M. (2013a). Against Phenomenal Conservatism. The Reasoner 7 (10): 117-118.

Mizrahi, M. (2013b). More Intuition Mongering. The Reasoner 7 (1): 5-6.

Mizrahi, M. (2014a). Phenomenal Conservatism, Justification, and Self-defeat. Logos and Episteme 5 (1): 103-110.

Mizrahi, M. (2014b). Phenomenal Conservatism and Self-defeat Arguments: A Reply to Huemer. Logos and Episteme 5 (3): 343-350.

Mizrahi, M. (2014c). Are Seemings Trustworthy? A Reply to Piazza. The Reasoner 8 (9): 100101.

Mizrahi, M. (2014d). Does the Method of Cases Rest on a Mistake? Review of Philosophy and Psychology 5 (2): 183-197.

Mizrahi, M. (2014e). Against Phenomenal Conservatism: a Reply to Moretti. The Reasoner 8 (3): 26.

Mizrahi, M. (2015a). On appeals to intuition: a reply to Muñoz-Suárez. The Reasoner 9 (2): 12 13.

Mizrahi, M. (2015b). Don't Believe the Hype: Why Should Philosophical Theories Yield to Intuitions? Teorema: International Journal of Philosophy 34 (3): 141-158.

Mizrahi, M. (2015c). Three Arguments Against the Expertise Defense. Metaphilosophy 46 (1): $52-64$.

Morell, J. D. (1847). An Historical and Critical View of the Speculative Philosophy of Europe in the Nineteenth Century. Vol. I. Second Edition. New York: Robert Carter.

Moretti, L. (2015). Phenomenal Conservatism. Analysis 75 (2): 296-309.

Nado, J. (2016). The Intuition Deniers. Philosophical Studies 173 (3): 781-800.

Pust, J. (2000). Intuitions as Evidence. New York: Garland. 
Reid, T. (1819). Essays on the Power of the Human Mind: to Which Are Prefixed an Essay on Quantity, and an Analysis of Aristotle's Logic. Edinburgh: Bell \& Bradfute.

Sarch, A. (2010). Bealer and the Autonomy of Philosophy. Synthese 172 (3): 451-474.

Sidgwick, H. (1874). The Methods of Ethics. London: Macmillan and Co.

Sidgwick, H. (1876). Professor Calderwood on Intuitionism in Morals. Mind 1 (4): 563-566.

Sosa, E. (1996). Rational Intuition: Bealer on Its Nature and Epistemic Status. Philosophical Studies 81 (2): 151-162.

Sosa, E. (2007). Experimental Philosophy and Philosophical Intuition. Philosophical Studies 132 (1): 99-107.

Textor, M. (2009). Devitt on the Epistemic Authority of Linguistic Intuitions. Erkenntnis 71 (3): 395-405.

Williamson, T. (2007). The Philosophy of Philosophy. Oxford: Blackwell. 